\title{
An axiomatic analysis of the papal conclave
}

\section{Andrew Mackenzie ${ }^{1}$}

Received: 26 January 2018 / Accepted: 12 February 2019 / Published online: 27 February 2019

(c) The Author(s) 2019

\begin{abstract}
In the Roman Catholic Church, the pope is elected by the (cardinal) electors through "scrutiny," where each elector casts an anonymous nomination. Using historical documents, we argue that a guiding principle for the church has been the protection of electors from the temptation to defy God through dishonest nomination. Based on axiomatic analysis involving this principle, we recommend that the church overturn the changes of Pope Pius XII to reinstate the scrutiny of Pope Gregory XV, and argue that randomization in the case of deadlock merits consideration.
\end{abstract}

Keywords Pope $\cdot$ Conclave $\cdot$ Mechanism design · Impartiality

JEL Classification Z12 · K16 · D82 - D71

\section{Introduction}

Dominentur nobis regulae, non regulis dominemur: simus subjecti canonibus, cum canonum praecepta servamus. ${ }^{1}$

\footnotetext{
${ }^{1}$ Quoted from the epistle of Pope Celestine I to the bishops of Illyricum (Pope Celestine I 428). My translation: "The rules should govern us, not the other way around: we should be submitted to the canons while we safeguard their principles."
}

I thank Corina Boar, Olga Gorelkina, Joseph Kaboski, Narayana Kocherlakota, Rida Laraki, Hervé Moulin, Romans Pancs, Marcus Pivato, Debraj Ray, Alvin Roth, Arunava Sen, Christian Trudeau, Rodrigo Velez, and two anonymous referees; seminar audiences at University of Windsor, University of Glasgow, the 2016 Meeting of the Society for Social Choice and Welfare, the 2017 D-TEA (Decision: Theory, Experiments and Applications) Workshop, and the 2018 Annual Congress of the European Economic Association; and especially William Thomson. Previous circulated drafts were titled "A Game of the Throne of Saint Peter" as a tribute to George R. R. Martin, whose writing has significantly influenced my thinking about succession.

$凶$ Andrew Mackenzie

a.mackenzie@maastrichtuniversity.nl

1 Department of Economics, Maastricht University, Maastricht, The Netherlands 
Every hierarchical institution that spans generations faces the question of succession: when the top office becomes vacant, how may it be occupied? Prominent answers throughout history include the hereditary laws of monarchies and the general elections of republics - but what if the monarchs are celibate, and what if the institution teaches students who are not allowed to vote? This is the case for the (Roman) Catholic Church, ${ }^{2}$ an institution boasting a membership today of over one billion. Its highest office is the papacy, the office of the pope, ${ }^{3}$ whose absolute authority among Catholics is founded on the dogma that he is the successor of Saint Peter. ${ }^{4}$ In recent decades, there has been a flurry of changes to the laws governing this succession, and our objective is to identify the underlying concerns in order to offer a proposal to the Catholic Church through axiomatic analysis.

The current practice is for the pope to be elected at a seclusive meeting of the cardinals known as a (papal) conclave. While conclaves have been standard for over seven centuries, ${ }^{5}$ modern conclave law is defined by documents written in the last twenty-five years. ${ }^{6}$ According to today's laws, the voters are the (cardinal) electorscardinals who are not yet eighty when the papacy becomes vacant-and they are isolated from the rest of the world for the duration of the election. Great measures are taken to keep them secluded when voting at the Sistine Chapel, when lodged at the Domus Sancta Marthae, and when traveling between the two. The election consists of a series of scrutinies, where each elector anonymously submits a ballot nominating one person. If someone receives at least two-thirds of the nominations and gives his assent, then he is the new pope, while if there is no such person, the ballots are burned with damp straw to create black smoke and another scrutiny is scheduled. After either thirty-three or thirty-four failed scrutinies (depending on whether or not the election begins on the afternoon of the first day), ${ }^{7}$ the two who received the most nominations in

\footnotetext{
2 The term catholic derives from the Greek katholikos, meaning "universal," and several churches call themselves catholic. For brevity, we abuse language, using Catholic as shorthand for Roman Catholic.

3 The papacy is also called the Apostolic See; the pope is also called the Bishop of Rome; the succession of the pope is also called the passing of the keys.

4 Quoting the 1965 Dogmatic Constitution of the Church (Pope Paul VI 1964): “[ ...]the Roman Pontiff has full, supreme and universal power over the Church [ ...]For our Lord placed Simon [who became Saint Peter] alone as the rock and the bearer of keys of the Church, and made him shepherd of the whole flock[...]" This refers to a quote of Jesus in the Bible (Matthew 16:18-19).

5 The papal conclave was first made a requirement for papal elections in the thirteenth century (Pope Gregory $X$ 1274). Though the practice was briefly suspended, it has remained law ever since its reinstatement by (Pope Celestine V 1294), a hermit who was made pope and resigned within six months only to be imprisoned until death by his successor. Incidentally, the next pope to resign of his own accord also changed conclave law; this was Pope Benedict XVI, who resigned in 2013.

6 The canon law governing conclaves is defined by the constitution Universi Dominici Gregis (Pope John Paul II 1996) and two amendments (Pope Benedict XVI 2007, 2013).

7 Though this is the usual reading, it may be inaccurate. The amended Clause 75 regarding two finalists (Pope Benedict XVI 2013) is enacted according to the original constitution (Pope John Paul II 1996). By Clause 74, this occurs after three series of seven scrutinies, which in turn occur after three days of scrutinies as described in Clauses 62-73. According to Clause 63: "Should the election begin on the afternoon of the first day, only one [scrutiny] is to be held; then, on the following days, if no one was elected on the first [scrutiny], two [scrutinies] shall be held in the morning and two in the afternoon." One reading is that the first three days either consist of $1+4+4$ scrutinies or $4+4+4$ scrutinies, in which case the two-finalist clause is enacted either after 30 or 33 failed scrutinies.
} 
this final scrutiny ${ }^{8}$ become finalists. Thereafter, at each deadlock scrutiny (our term), these finalists do not vote and the other electors may only nominate one of them, and this continues until a finalist receives at least two-thirds of the nominations and accepts the papacy.

Recent popes have attended to a number of facets of conclave law, including who can vote,${ }^{9}$ alternative election methods, ${ }^{10}$ whether a secular ruler can veto a candidate, ${ }^{11}$ the structure of scrutiny, ${ }^{12}$ and how to handle deadlock. ${ }^{13}$ Despite some vacillation on these topics, there has been an unambiguous trend toward a series of scrutinies with a special election method for deadlock. We therefore restrict attention to such conclave formats, separately addressing (i) the structure of scrutiny, and (ii) how deadlock should be handled.

In forming our proposal, we pursue an approach that is subtly different from the standard one for axiomatic analysis of institutions: we do not address the normative question of which principles our institution should hold, but rather the positive question of which principles it does hold. This distinction merits emphasis because addressing the normative question has been essential to many recent applications of mechanism design to specific institutions-from the advocacy of efficiency in response to unnecessary deaths due to untraded donor kidneys (Roth et al. 2004), to the advocacy of strategy-proofness in response to the gaming of children's futures in school choice (Balinski and Sönmez 1999; Abdulkadiroğlu and Sönmez 1999, 2003), to the advocacy of respecting improvements in response to the deliberate exam-failing of military cadets seeking their top branches (Sönmez 2013; Sönmez and Switzer 2013). But in each of these cases economists began by observing a feature of the status quo that could be uncontroversially described as perverse, and that is not the case here-due to the seclusion of the conclave, all that we can observe is the outcome, and we do not claim that the modern conclave selects popes poorly. We simply observe a lack of conviction in the modern conclave suggested by recent changes, and we seek not to

\footnotetext{
${ }^{8}$ It is not specified what happens if there is not a unique pair with the most nominations, as in the case of (for example) a three-way tie.

9 Pope Paul VI introduced the age restriction for cardinals to be electors (Pope Paul VI 1970, 1975); Duffy (1997) proposes that this was to reduce the influence of cardinals appointed by Pope Pius XII.

10 Pope Pius X (1904b) abolished accessus, where immediately after a scrutiny each elector may replace his nomination with one for a current nominee. Pope John Paul II (1996) abolished (i) acclamation, where the electors simultaneously and unanimously declare aloud the new pope, and (ii) compromise, where the electors unanimously agree on a small subset of themselves to be representatives, and at least two-thirds of these representatives nominate the new pope.

11 Pope Pius X (1904a) abolished the jus exclusivae: the right for a head of state to announce, through a cardinal, that he vetoed a particular candidate. It was last used in the 1903 conclave, which elected the pope who abolished it, when Emperor Franz Joseph I of Austria vetoed Cardinal Rampolla. Lonyay (1949) proposes that Rampolla was vetoed because over a decade earlier he had opposed the Christian burial of the emperor's first heir, Crown Prince Rudolf, on the grounds of his apparent suicide. Incidentally, the same emperor had another heir whose sudden death sparked conflict: Archduke Franz Ferdinand.

12 There have been changes to the ballot layout, the winning threshold, and whether or not an elector may vote for himself - as we shall discuss in detail.

13 Having abolished the remaining alternatives to scrutiny, Pope John Paul II (1996) introduced deadlock scrutinies with simple majority. Pope Benedict XVI (2013) raised the threshold to two-thirds of the electors.
} 
propose new principles for the Catholic Church but rather to help the church on the basis of its own principles. ${ }^{14}$

In Sect. 2, using decrees of ecumenical councils, conclave law, church ceremonies, and other historical writings, we argue that a guiding principle for conclave design is that electors should be protected from the temptation to defy God: despite being the living men best-trained to let God speak through them, the electors are but men, and therefore sinners, and therefore imperfect instruments through which God may communicate. Specifically, an elector is called to nominate the person he believes God would have him nominate, and the Holy Spirit may reveal this person to him, yet the elector may face temptation to sin by instead nominating another. The conclave's defining feature, its absolute seclusion, serves to protect electors from outside influences, but this does not provide protection from one's peers or from one's self. We argue that these additional protections were provided by the scrutiny of 1621-1945 (Pope Gregory XV 1621, 1622), but since then electors have been unprotected from the temptation of personal ambition due to a simplification of the ballot layout (Pope Pius XII 1945).

In Sect. 3, we analyze scrutiny by adapting a recent model (Holzman and Moulin 2013) to allow the possibility of declaring the election inconclusive with black smoke. Protection from peers and self are then translated into axioms:

- Voters in elections across the world are protected from the bribes and threats of peers through the use of anonymous ballots (Holzman and Moulin 2013), and scrutiny should be no different.

- Personal ambition for the papal tiara might tempt an elector to vote not as he believes God would have him, but to instead vote in hopes of crowning himself. This concern is greatly mitigated if the scrutiny is impartial - that is, if whether or not a given elector wins is determined solely by the votes of his peers (de Clippel et al. 2008; Holzman and Moulin 2013).

To define our focal class of scrutinies, let $n$ denote the number of electors. A supermajority scrutiny is specified by a number greater than $\frac{1}{2} n$ but no greater than $n$ called its threshold; if somebody receives at least this many votes, he is elected; otherwise, there is black smoke. Both the modern scrutiny and the scrutiny of 1621-1945 are supermajority scrutinies with threshold $\frac{2}{3} n$; the difference is that the former allows self-nomination while the latter does not.

We first analyze the modern format, and our findings are disappointing. Not only does the modern scrutiny violate impartiality, but so long as self-nomination is allowed, the only scrutinies which satisfy both impartiality and anonymous ballots are constant; moreover, if anonymous ballots is replaced with the requirement that the electors are treated symmetrically as candidates, then only the constant black smoke scrutiny remains (Theorem 1). Our conclusion is that the current scrutiny is deficient and that

\footnotetext{
14 If anything, principles have typically flowed in the opposite direction, from religions to economists, and for evidence one need not look beyond the axiomatic literature. The analysis of claims problems, where an arbitrator must divide an estate among overpromised heirs, began with careful consideration of recommendations from the Talmud (O'Neill 1982; Aumann and Maschler 1985). The distillation of axioms and game-theoretic foundations from these recommendations inspired a vast literature whose findings now fill a book (Thomson 2019); for a recent survey, see Thomson (2015).
} 
moreover a simple adjustment to the processing of ballots will not suffice to repair it: the format must be changed.

We then analyze the format where self-nomination is prohibited-which was used for over three centuries - and here our findings are much more encouraging. Using additional axioms capturing that messages should be interpreted as nominations, that consensus should be respected, and that electors should be treated symmetrically, we provide three tight characterizations of supermajority scrutinies (Theorem 2). We therefore not only endorse the format of 1621-1945, but also endorse the particular scrutiny used during that period.

In Sect. 4, we focus on deadlock. After providing several criticisms of the current practice, we use the principles we have identified, previous results in the literature (Holzman and Moulin 2013; Mackenzie 2015), and a passage from the Bible to argue that randomization merits consideration. Section 5 concludes.

\section{Historical analysis}

\subsection{The 1945 laws of Pius XII}

The greatest vacillation in recent conclave law has concerned the minimum number of votes required to be elected pope. The threshold was $\frac{2}{3} n$ in 1945 , as it had been for over seven centuries, when Pope Pius XII increased it to $\frac{2}{3} n+1$ (Pope Pius XII 1945). His direct successor reinstated the original threshold (Pope John XXIII 1962), but his direct successor reinstated the increase (Pope Paul VI 1975). The next pope, John Paul I, did not address the topic in the 33 days between his coronation and his death, but the next pope reinstated the $\frac{2}{3} n$ threshold once again (Pope John Paul II 1996). What was this about?

The $\frac{2}{3} n$ threshold, which predates the conclave itself, was originally a measure to protect the church from schism. It was first introduced at an ecumenical council: a formal gathering of important members of the church across the world to authoritatively settle critical matters. These are rare events, with only twenty-one of them recognized by the Catholic Church in its entire history, and by Catholic dogma their decrees are infallible (that is, immune to human error). ${ }^{15}$ The $\frac{2}{3} n$ threshold was decreed as the first canon of the Third Lateran Council; as translated in Pope Alexander III (1179):

Although clear enough decrees have been handed down by our predecessors to avoid dissensions in the choice of a sovereign pontiff, nevertheless in spite of these, because through wicked and reckless ambition the church has often suffered serious division, we too, in order to avoid this evil, on the advice of our brethren and with the approval of the sacred council, have decided that some addition must be made. Therefore, we decree that if [...]there cannot be full agreement among the cardinals on a successor to the papacy[...] that person

\footnotetext{
15 The dogma of conciliar infallibility was most recently stated at the latest ecumenical council, the Second Vatican Council (Pope Paul VI 1964, Clause 25, second paragraph).
} 
shall be held as Roman pontiff who has been chosen and received by the two thirds.

That protection from schism was a priority for this particular council is not surprising. The presiding pope, Alexander III, had just reconciled with Holy Roman Emperor Frederick I, who had named three antipopes-popes that Catholics today do not recognize-against him. ${ }^{16}$ The decree achieved its objective with remarkable success, as more than eight centuries have passed without a schism caused by different factions of cardinals simultaneously electing different popes. Though there were later schisms caused by other sorts of internal conflicts, ${ }^{17}$ it has been over half a millennium since the last serious schism.

Why, then, was the threshold changed in 1945 ? Was it due to the extraordinary circumstances of the times? We reject this as unlikely. It is true that Pius XII reigned in Vatican City, a sovereign nation within the city of Rome, and that this city was occupied during World War II-both by the Axis in 1943 and by the Allies in 1944. But the threshold change did not at all impact secular influence in conclave, and the next popes continued to address this topic in the decades following the war.

Our hypothesis is that Pius XII changed the threshold as part of his response to a 1904 conclave change of Pius X (Pope Pius X 1904b). Previously, ballots featured signatures and codes: each elector wrote not only the name of his nominee, but also his own name and an identifying phrase. This additional information was concealed for scrutiny, but was used in a post-scrutiny method of election called accessus: each elector could go to his ballot, prove that it was his, and recast it for someone else who had been nominated. The purpose of accessus was to help the electors reach a consensus more quickly, but it proved more inconvenient than helpful, as Pius X explained when he abolished it in 1904.

Without accessus, ballots were used only for scrutiny, and it seems that Pius XII simplified the ballots to only include nominees for this reason. A side effect of this simplification was that the prohibition against self-nomination became unenforceable, and there is evidence that this was the reason for the threshold change. In Clause 68 of his constitution, Pius XII explains that the purpose of the threshold increase is to avoid any occasion of doubt that the vote of the winner is among the two-thirds of the electors that nominate him (Pope Pius XII 1945), ${ }^{18}$ citing Aeterni Patris (Pope Gregory XV 1621).

\footnotetext{
16 Frederick I was known as Barbarossa, or "Red Beard." He reconciled with Alexander III only upon his defeat at the Battle of Legnano.

17 The Western Schism occurred when the very cardinals who elected Pope Urban VI claimed they did so under duress and then crowned Antipope Clement VII in 1378; over the course of this schism, there were additional elections of antipopes. Another schism occurred when Antipope Felix V was crowned in 1439 during the reign of Pope Eugene IV by a council that claimed it was ecumenical, and that moreover the authority of an ecumenical council was greater than that of the pope.

18 For the reader who consults the original Latin: in the same sentence, Pius XII states that this should be true both in scrutiny and in compromise, and goes on to specify that if the winner is an elector, he should still be counted in calculating the threshold.
} 


\subsection{The 1621-1622 laws of Gregory XV}

As the first thorough constitutions governing the election of a pope written by a pope, Aeterni Patris (Pope Gregory XV 1621) and Decet Romanum Pontificem (Pope Gregory XV 1622) form the foundation of the modern conclave. As cited in Pope Pius XII (1945), Clauses 2-3 of Aeterni Patris indeed decree that the winner should not be counted among the two-thirds of the electors that nominate him. But they then go further, decreeing that self-nomination is prohibited: nobody, whether in scrutiny, compromise, or accessus, should choose to vote for himself in any way. What was the reason for this?

Our explanation relies on the principle that each elector's vote is supposed to be guided by the Holy Spirit, a principle for which there is much evidence in the current constitution (Pope John Paul II 1996). The older cardinals who are not electors should be "supporting the work of the electors with fervent prayers and supplications to the Holy Spirit and imploring for them [the electors] the light needed to make their choice before God alone and with concern only for the salvation of souls, which in the Church must always be the supreme law" (introduction; Clause 85). The electors themselves invoke the Holy Spirit for help with the chant of Veni Creator as they enter the Sistine Chapel (Clause 50), which is the location for voting because "the electors can more easily dispose themselves to accept the interior movements of the Holy Spirit" as there "everything is conducive to an awareness of the presence of God" (introduction; Clause 51).

We propose that Gregory XV prohibited self-nomination out of concern that an elector could be tempted to resist the Holy Spirit - that is, the Holy Spirit might communicate to an elector whom he should nominate only for that elector to instead nominate another. There is much evidence of this indirectly in the laws of conclave, as we shall discuss, but there is also direct evidence in a ceremony that has been observed in conclaves ever since the prohibition: the oath that (with small modifications) appears in Clause 5 of Pope Gregory XV (1621), Clause 67 of Pope Pius X (1904b), Clause 78 of Pope Pius XII (1945), Clause 68 of Pope Paul VI (1975), and Clause 66 of Pope John Paul II (1996). In the current constitution, it reads:

I call as my witness Christ the Lord who will be my judge, that my vote is given to the one who before God I think should be elected.

This oath, said by each elector before he casts his ballot, is a direct acknowledgment in the church's constitutions that even a cardinal at a papal conclave might believe God would have him do one thing but instead do another.

Temptation to deviate from God's choice could come from outside of conclave, from another elector, or from one's self. There is strong evidence that each is a grave concern for the church.

- Temptation from outsiders. Throughout the centuries, secular rulers such as kings and emperors have had great interest in the choice of pope. The conclave's defining feature, its absolute seclusion, serves to protect the electors from outside influence. In the current constitution, anybody who violates the secrecy of the conclave is 
punished severely by automatic excommunication, ${ }^{19}$ as is anybody who so much as hints at the preferences of a secular ruler while in conclave. ${ }^{20}$

- Temptation from peers. Bribes in papal elections fall under the sin of simony, ${ }^{21}$ the topic of the first canon of the Second Lateran Council. As translated in Pope Innocent II (1139):

We decree that if anyone has been ordained simoniacally, he is to forfeit entirely the office which he illicitly usurped.

Though accusations of simony in papal elections are unsurprisingly controversial, some have gained broad acceptance in modern culture. ${ }^{22}$ Today, simony is punished by automatic excommunication, ${ }^{23}$ as is participation in any kind of voting pact. $^{24}$

- Temptation from self. The concern is an elector who does not believe he is the best choice for the church, but nevertheless selfishly covets the papacy, as such an elector might be convinced-whether or not it is true-that instead of sharing his honest opinion he can cast the decisive vote for himself. Such a concern is suggested as early as the fourth century by a historian, whose translated report reads, "[ ...]men who covet this office [the papacy] in order to fulfill their ambitions may well struggle for it with every resource at their disposal" (Marcellinus circa 352), and echoes the statement in the canon of the Third Lateran Council that the church suffers through "wicked and reckless ambition." We interpret the prohibition of self-nomination as a response to this concern.

The simplest approach to controlling a particular elector-a promise or threat conditional on how he votes-should not be available to anybody outside the conclave

\footnotetext{
19 From Clause 58 of Pope John Paul II (1996): "[...][those] who directly or indirectly could in any way violate secrecy — whether by words or writing, by signs or in any other way-are absolutely obliged to avoid this, lest they incur the penalty of excommunication latae setentiae [...]

${ }^{20}$ From Clause 80 of Pope John Paul II (1996): “[ ...]I wish to confirm the provisions made by my Predecessors for the purpose of excluding any external interference in the election of the Supreme Pontiff. Therefore, in virtue of holy obedience and under pain of excommunication latae setentiae, I again forbid each and every Cardinal elector [...]to accept under any pretext whatsoever, from any civil authority whatsoever, the task of proposing the veto or the so-called exclusiva, even under the guise of a simple desire, or to reveal such either to the entire electoral body assembled together or to individual electors, in writing or by word of mouth, either directly and personally or indirectly through others, both before the election begins and for its duration."

21 More broadly, the sin of simony covers the exchange of the spiritual for the temporal. The sin is named for Simon Magus, who according to the Bible offered the apostles Peter and John money in exchange for the ability to impart the Holy Spirit to others through touch (Acts 8:9-24). The Catholic view that it is sinful to make such an exchange might help explain why some transactions today are considered repugnant (Roth 2007), such as organ sales and prostitution.

22 Perhaps Cardinal Borgia, elected Pope Alexander VI in 1492, is the most notable example.

${ }^{23}$ From Clause 78 of Pope John Paul II (1996): "If-God forbid-in the election of the Roman Pontiff the crime of simony were to be perpetrated, I decree and declare that all those guilty thereof shall incur excommunication latae setentiae."

${ }^{24}$ From Clause 81 of Pope John Paul II (1996): "The Cardinal electors shall further abstain from any form of pact, agreement, promise or other commitment of any kind which could oblige them to give or deny their vote to a person or persons[ .... ]and I hereby impose the penalty of excommunication latae sententiae upon those who violate this prohibition."
} 
GREGORIUS DECIMUSQUINTUS.

407

EXEMPLUM F A CIEI SCHEDULE SCRUTINIT.

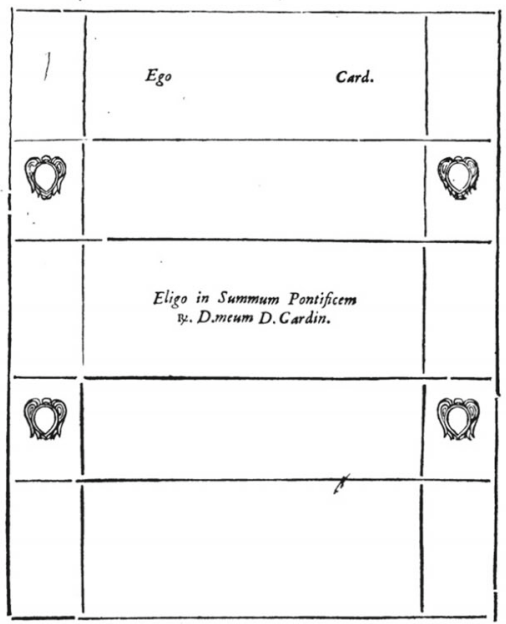

GREGORIUS DECIMUSQUINTUS. $40^{\circ}$

EXEMPLUM T.E R G I SCHEDULARUM SCRUTINII, \& Acceffus.

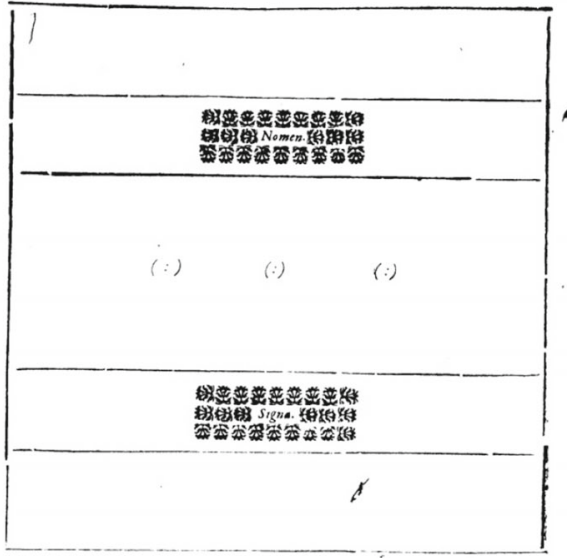

Fig. 1 The ballot layout of Pope Gregory XV (1622) as printed in 1692. The left image shows the front of the ballot, where the elector writes. The right image shows the back, which is left alone; the image is in fact misprinted, as Nomen [Name] should be at the bottom and Signa [Emblems] should be at the top. Note that if two ballots were placed next to each other, one showing the front and one showing the back, the horizontal lines would not align. To go from the left image to the right, flip the ballot not as a page of a book, but by rotating it about its top. The middle column of the front has five rows. In the top row is printed Ego Card. [I, Cardinal...]; here the elector writes his own name. In the middle row is printed Eligo in Summum Pontificem R. D. meum D. Cardin. [...choose for the Most Reverend Lord Supreme Pontiff my Lord Cardinal...]; here the elector writes his nominee. The bottom row is blank; here the elector writes a code which is used in accessus. After completing his ballot, the elector folds along the top and bottom horizontal lines of the front so that his own name and his code are concealed but his nominee is not. The ballot is then sealed

because it requires information that is unobservable. Similarly, an elector can be protected from the bribes or threats of his peers in the same way that voters in elections across the world are: through use of a secret ballot. Finally, an elector can be protected from temptation due to personal ambition if whether or not he wins a given scrutiny is determined solely by his peers; this is the case for supermajority scrutinies precisely when self-nomination is prohibited. But this raises a puzzle: if a secret ballot is used, how can this prohibition be enforced ${ }^{25}$

Gregory XV provided a clever solution through the design of a ballot that allowed an elector to sign and then conceal his signature (Fig. 1). In the exceptional event that an elector received exactly the minimum number of votes required to win, the signatures would be checked to verify that he did not nominate himself; otherwise, there was no need. Thus in scrutiny, a new pope was determined using a secret ballot,

\footnotetext{
25 Though we view secret voting as protection from bribes and threats, others have viewed public voting as protection against strategic voting when voters know each other. This debate goes back at least to Ramon Lull and Nicolas of Cusa, over five centuries before Condorcet and Borda (McLean 1990).
} 
while the signatures were used exclusively for enforcement of the self-nomination prohibition.

When Pius XII simplified the ballot layout, he made the prohibition against selfnomination unenforceable, and for the first time in the history of the church, the first canon of the Third Lateran Council was incompatible with Clauses 2-3 of Aeterni

Patris. Because $\frac{2}{3} n$ nominations became unequal to $\frac{2}{3} n$ peer nominations, an ancient ecumenical council became incompatible with the founding documents of the modern conclave, resulting in church law vacillation where popes directly contradicted their direct predecessors. That said, we will see that axiomatic analysis involving the church's principles leads to a proposal where the Third Lateran Council and the decrees of Gregory XV are once again reconciled.

\section{Scrutiny design}

\subsection{Model}

Due to the unambiguous historical trend toward conclaves that consist of a series of scrutinies together with a special method for deadlock, we restrict attention to such conclave formats. In particular, we have in mind the following sort of dynamic procedure: in each scrutiny, each elector casts a nomination, and these nominations together determine a winner or black smoke. If there is a winner, then after the scrutiny he is asked to accept or decline the papacy. If a winner accepts, then the conclave ends; otherwise, the conclave continues. In the latter event, there is an opportunity for electors to discuss and pray, followed by either (i) another scrutiny (if there have not yet been enough scrutinies), or (ii) the deadlock method (if there have been enough scrutinies). In this section, we consider the design of scrutiny, while in Sect. 4 , we consider the design of the deadlock method.

Given the above discussion, it may be surprising to discover that the model we are about to introduce is in fact static. This reason is simple: in order to draw sharp conclusions about scrutiny design and deadlock design, we require only static hypotheses. Our analysis does not rely on, for example, any assumptions about differences in the information that electors have when the conclave begins, or about how beliefs are impacted by statements made between scrutinies, or about the influence of prayer, or about the patience of the electors. The omission of these important features is not due to neglect: by contrast, our analysis is robust to any further assumptions about them.

Formally, we analyze two formats of scrutiny in this section, both of which consist of:

- a finite set of electors, $N \equiv\{1,2, \ldots, i, j, k, \ldots, n\}$,

- the black smoke, denoted 0 , and

- a list of ballot spaces, $\left(B_{i}\right)_{i \in N}$, where for each $i \in N, B_{i} \subseteq N$.

As in the modern conclave, the black smoke is an outside option declaring the scrutiny inconclusive. Each elector $i$ selects a nominee $x_{i}$ from his ballot space $B_{i}$.

To keep our analysis focused on the central ideas of this article, we forbid the nomination of non-electors. Though this restriction is not law, the nomination of non- 
electors was for many years discouraged (see Fig. 1), and a non-cardinal has not been elected since Urban VI in 1378. More importantly, this restriction has no impact on the message of our article; it simply allows our main findings to be stated more directly.

The two formats we model, that of Pius XII (1945-present) and that of Gregory XV (1621-1945), are distinguished by whether or not self-nomination is permitted:

- Piusine ${ }^{26}$ format: for each $i \in N, B_{i} \equiv N$, and

- Gregorian format: $n \geq 2$ and for each $i \in N, B_{i} \equiv N \backslash\{i\}$.

When black smoke is disallowed, our model of the Gregorian format coincides with the model of Holzman and Moulin (2013); we discuss this further when analyzing deadlock in Sect. 4.

Each of the following definitions applies to both formats. The set of ballot profiles is $B \equiv \times B_{i}$, and a scrutiny is a mapping $\varphi: B \rightarrow N \cup\{0\}$ that associates each ballot profile $x \in B$ with an outcome $\varphi(x)$, which is either (i) a winner, who will be asked to be pope, or (ii) black smoke declaring the scrutiny inconclusive.

We emphasize that (i) in the event of a winner, the winner must then choose whether to accept or decline the papacy, and if he declines the conclave continues; and (ii) in the event of black smoke, the conclave necessarily continues. The interpretation of continuation varies with the round of scrutiny - in round $t$, it either means moving to the scrutiny of round $t+1$ or moving to the deadlock method. Though we formulate our axioms in this static model, it is important to keep this dynamic interpretation in mind when evaluating our axioms.

\subsection{Axioms}

An axiom is a mathematical property of a scrutiny that captures an idea. Each of the following axioms has been considered previously in the literature, ${ }^{27}$ and is here stated for both the Piusine and Gregorian format-with the exception of positive unanimity, which is stated only for the Gregorian format.

Our first two axioms capture the principles identified in Sect. 2: electors should be protected from temptation due to self and due to peers. We then introduce five additional axioms that capture basic normative criteria that are standard across many elections, and that moreover have traditionally been respected in conclaves. We briefly revisit this latter point after introducing the axioms.

To capture the idea that electors should be protected from temptation due to personal ambition, we require that an elector's nomination does not impact whether or not he is asked to be pope after the current round of scrutiny. Formally, let us write $x_{-i}$ to

\footnotetext{
26 There are many eponymous adjectives associated with popes, such as Petrine for the cross of Saint Peter, Gregorian for the chant of Gregory I and the calendar of Gregory XIII, and Sistine for the chapel of Sixtus IV. But to our knowledge, there is no such adjective for any Pius; we propose Piusine.

27 In related models, impartiality was proposed by de Clippel et al. (2008), name independence by Ng and Sun (2003), candidate neutrality by Mackenzie (2015), and all of our other axioms by Holzman and Moulin (2013). Mihara (1997) is perhaps the first to define a symmetry axiom using all permutations, except when the permuted result is inadmissible, in a nontrivial model; he considered an infinite voter setting where previous works had considered only measurable permutations.
} 
denote a profile of one ballot from each elector except $i$, and write $B_{-i}$ to denote the set of all such profiles. Our axiom is as follows:

IMPARTIALITY: For each $i \in N$, each pair $x_{i}, x_{i}^{\prime} \in B_{i}$, and each $x_{-i} \in B_{-i}$,

$$
\varphi\left(x_{i}, x_{-i}\right)=i \Leftrightarrow \varphi\left(x_{i}^{\prime}, x_{-i}\right)=i
$$

We remark that this axiom does not assert that all conceivable temptation due to personal ambition be removed from the conclave, as it does allow an elector's nomination to impact the outcome of the scrutiny. For example, a given elector may believe that preventing one of his peers from winning the current scrutiny will ultimately lead to a later scrutiny that he himself wins, or may believe that a dishonest nomination may improve his likelihood of winning in the deadlock method. Our axiom simply captures the weak requirement that, at the very least, an elector should not face the temptation to crown himself in a given round. As we will see, even this weak requirement has sharp implications for scrutiny design.

To capture the idea that electors should be protected from bribes and threats of peers, we require that the outcome can be determined using only the scores, allowing the scrutiny to be a secret ballot. Formally, let us say that an elector's score is the number of nominations he receives. Given a ballot profile $x \in B$, we write $\mathcal{S}(x)$ for the score profile of $x, \mathcal{S}_{i}(x) \equiv\left|\left\{j \in N \mid x_{j}=i\right\}\right|$. Our axiom is as follows:

ANONYMOUS BALLOTS: For each pair $x, x^{\prime} \in B$,

$$
\mathcal{S}(x)=\mathcal{S}\left(x^{\prime}\right) \text { implies } \varphi(x)=\varphi\left(x^{\prime}\right) .
$$

Our third axiom captures the simple idea that ballots are interpreted as nominations: Monotonicity: For each pair $i, j \in N$, each $x \in B$, and each $x_{i}^{\prime} \in B_{i}$,

$$
\varphi(x)=j \text { and } x_{i}^{\prime}=j \Rightarrow \varphi\left(x_{i}^{\prime}, x_{-i}\right)=j .
$$

Our next two axioms capture the idea that consensus be respected. First, if an elector is nominated by all his peers, then he should be asked to be pope. Because we only analyze this axiom when self-nomination is prohibited, we can provide the following simple statement:

POSITIVE UNANIMITY [GREGORIAN FORMAT]: For each $i \in N$ and each $x \in B$,

$$
\mathcal{S}_{i}(x)=n-1 \Rightarrow \varphi(x)=i
$$

Second, an elector nominated by nobody should not be asked to be pope:

NeGATIVE UNANIMITY: For each $i \in N$ and each $x \in B$,

$$
\mathcal{S}_{i}(x)=0 \Rightarrow \varphi(x) \neq i
$$

Our final two axioms capture the idea that electors should be treated symmetrically. Formally, let $\mathfrak{S}_{N}$ denote the symmetric group consisting of all permutations on $N$, 
and let $\mathbb{1}$ denote the identity: for each $i \in N, \mathbb{1}(i)=i$. Given $x \in B$ and $\sigma, \tau \in \mathfrak{S}_{N}$, let $x^{\sigma, \tau} \in N^{N}$ be defined as follows: for each $i \in N, x_{\sigma(i)}^{\sigma, \tau} \equiv \tau\left(x_{i}\right)$. Observe that for the Gregorian format, $x$ may be a ballot profile while $x^{\sigma, \tau}$ is not, as there may be some $i \in N$ for which $x_{i}^{\sigma, \tau}=i$. First, electors should be treated symmetrically insofar as they are candidates: $:^{28}$

CANDidAte NeUtRality: For each $x \in B$ and each $\sigma \in \mathfrak{S}_{N}$,

$$
\text { if } x^{\mathbb{1}, \sigma} \in B \text { and } \varphi(x) \in N \text {, then } \varphi\left(x^{\mathbb{1}, \sigma}\right)=\sigma(\varphi(x)) \text {. }
$$

Second, the scrutiny should not distinguish between any two electors on the basis of name a priori:

NAME INDEPENDENCE: For each $x \in B$ and each $\sigma \in \mathfrak{S}_{N}$,

$$
\text { if } \varphi(x) \in N \text {, then } \varphi\left(x^{\sigma, \sigma}\right)=\sigma(\varphi(x)) \text {. }
$$

We remark that this axiom immediately implies that if $\varphi(x)=0$, then $\varphi\left(x^{\sigma, \sigma}\right)=0$.

Each of these axioms is satisfied by the scrutiny of Gregory XV. Moreover, while only impartiality and anonymous ballots were specifically identified from our historical analysis, others are suggestive of conclave tradition. For example, monotonicity is compatible with the word Eligo — "I choose"-which has been specifically required in scrutinies and other methods for centuries; positive unanimity is reminiscent of acclamation, a former method of election where the electors simultaneously and unanimously declare aloud the new pope; and name independence prohibits treating an elector differently at the start of scrutiny, disallowing both (i) a pope naming his successor; and (ii) the jus exclusivae, where a secular ruler vetoes an elector.

\subsection{Analysis of Piusine format}

We begin by providing several examples of scrutinies in the Piusine format. First, we introduce the class to which the modern scrutiny belongs, each member indexed by a threshold:

SUPERMAJORITY SCRUTINY WITH INDEX $t, n \geq t>\frac{n}{2}$ : For each $x \in B$ and each $i \in N$,

$$
\varphi(x)=i \text { if and only if } \mathcal{S}_{i}(x) \geq t .
$$

The modern scrutiny has index $\frac{2}{3} n$, while the supermajority scrutiny with index $\frac{2}{3} n+1$ was used in the last century.

\footnotetext{
28 The analogous symmetry axiom that requires electors are treated symmetrically insofar as they are voters (Mackenzie 2015) is logically equivalent to anonymous ballots for both the Piusine and Gregorian formats, and the proof is straightforward.
} 
Next, we introduce a class of constant scrutinies, each indexed by an elector who always wins:

FIXED- WINNER SCRUTINY INDEXED BY $i \in N$ : For each $x \in B$,

$$
\varphi(x)=i
$$

In such a scrutiny, the winner is determined without input from the cardinal electors at all. This could happen, for example, if the pope designated his successor. Though this did happen in the early church, ${ }^{29}$ the pope has been selected by the cardinals for nearly a millenium (Pope Nicholas II 1059).

Finally, we introduce the constant rule that always selects black smoke:

BLACK SMOKE SCRUTINY: For each $x \in B$,

$$
\varphi(x)=0 .
$$

This is a scrutiny by definition, though it clearly is of no practical use.

It is clear that the modern scrutiny is not impartial, as an elector can determine whether or not he wins when his peers have made him one vote short of winning. In fact, this defect deeply pervades the modern format altogether:

Theorem 1 For the Piusine format with at least two electors, an impartial scrutiny satisfies

- anonymous ballots if and only if it is a fixed-winner scrutiny or the black smoke scrutiny, and

- candidate neutrality if and only if it is the black smoke scrutiny.

The proof is in Appendix A. Our conclusion is simple: the format of scrutiny should be changed. ${ }^{30}$

\subsection{Analysis of Gregorian format}

For the Gregorian format, the definitions of the fixed-winner scrutinies and the black smoke scrutiny are as written in Sect. 3.3; the difference is that the space of ballot profiles $B$ has changed with the prohibition of self-nomination. There is an additional difference for the definition of the supermajority scrutiny: the threshold $t$ can no longer be $n$; it must now satisfy $n-1 \geq t>\frac{1}{2} n$. The scrutiny of 1621-1945 is the member of the supermajority class with index $\frac{2}{3} n$.

It is clear that each supermajority scrutiny satisfies all of our axioms. This raises a natural question: does any other scrutiny for the Gregorian format? The answer is no.

\footnotetext{
29 For example, it is known that Felix IV designated Boniface II (Pope Felix IV circa 530).

30 We remark that the first part of the theorem extends to the case $n=1$, but the second part does not: when there is a single elector, the unique fixed-winner rule satisfies all of our axioms. In this extraordinary scenario, the Piusine format outperforms the Gregorian format, as with the latter format the sole elector would be unable to cast a nomination.
} 
In fact, the supermajority class is distinguished using only some of our axioms, the other axioms implied through logical relationships:

Theorem 2 For the Gregorian format with at least three electors, the following are equivalent:

- $\varphi$ is a supermajority scrutiny;

- $\varphi$ satisfies impartiality, monotonicity, positive unanimity, anonymous ballots, and candidate neutrality;

- $\varphi$ satisfies impartiality, monotonicity, positive unanimity, anonymous ballots, and name independence;

- $\varphi$ satisfies impartiality, monotonicity, positive unanimity, candidate neutrality, and name independence.

Moreover, if there are at least seven electors, then each of these three characterizations is tight.

The proof is in Appendix B. Within the supermajority class, a rule is selected by specifying a threshold, and for the Gregorian format, both the Third Lateran Council and Gregory XV agree that this threshold should be $\frac{2}{3} n .^{31}$

In a similar finding, May (1952) considers the problem of aggregating rankings over two social alternatives, and proves that simple majority is the only rule satisfying anonymity, neutrality, and a strong version of monotonicity. Though we consider rules with larger domains and ranges, similar axioms nevertheless lead to a small class of similar rules when incentives are taken into consideration through impartiality. In fact, analogous results hold for a variety of domain-range settings where agents approve of several peers and at least one prize, but possibly several, must be awarded (Suzuki and Horita 2016).

Because of our finding, we are able not only to endorse the Gregorian format on the basis of the principles we have identified, but also to endorse the specific scrutiny of 1621-1945. That does not necessarily mean that electors must sign their ballots; we discuss this in the conclusion.

\section{Deadlock}

After enough failed scrutinies, the conclave moves to its deadlock method. The current method is as follows: the two with the most nominations in the final standard scrutiny become finalists; thereafter, at each deadlock scrutiny, a voter may only nominate a finalist; this continues until one of the finalists receives at least two-thirds of the nominations and accepts the papacy. That said, there are a few potential concerns with this method.

\footnotetext{
31 We remark that when there is one elector, the Gregorian format is unavailable, and when there are two electors, the only scrutinies are the fixed-winner scrutinies and the black smoke scrutiny.
} 
- The final standard scrutiny may not reveal two finalists. For example, there could be a four-way tie, or there may be two electors tied for second place. The current law does not address all possibilities. ${ }^{32}$

- The conclave is not guaranteed to end by a particular date. When John Paul II introduced deadlock scrutinies, he required only that a finalist receive a majority of the votes, essentially guaranteeing the conclave ends on the date of the first deadlock scrutiny. This meant, however, that a patient majority of electors could block all standard scrutinies to make their candidate a finalist and elect him, effectively removing the requirement that the winner receives two-thirds of the nominations. This appears to be the reason that Benedict XVI raised the threshold for deadlock scrutiny to two-thirds of the electors, but the trade-off is that this reintroduces the possibility that a conclave could continue indefinitely.

- Narrowing down to two finalists could make compromise difficult. On some future date, the church may find its electors polarized. In such a climate, a moderate candidate may best serve the church and protect it from schism. But such a compromise would be impossible if the two finalists held positions at opposite extremes.

- Over the course of deadlock scrutinies, one of the finalists may die. Though remote, this possibility is more likely in a polarized conclave that has trouble reaching a consensus - a process which can take years. ${ }^{33}$ As the current constitution does not address this possibility, there is room for argument that the surviving finalist should become the pope. Naturally, if one of two finalists in a polarized conclave were to die for any reason, accusations of murder could do tremendous damage to the church and perhaps even cause schism.

Due to the above concerns, we consider the problem of designing an alternative method of handling deadlock.

To directly address the concern that the conclave is not guaranteed to end by a particular date, we consider the design of a special decisive scrutiny, where all electors participate as both voters and candidates, after which someone is immediately asked to be pope. Such a scrutiny could be a used as a last resort after a sufficient number of failed standard scrutinies, as with the current deadlock method.

Formally, we consider our previous model and introduce an additional axiom forbidding the use of black smoke:

DECISIVENESS: For each $x \in B, \varphi(x) \in N$.

In all its centuries, the conclave has never featured such a scrutiny. This history is unsurprising, for in fact each decisive scrutiny is defective according to the principles we have identified as evidenced by the following three findings. First, no decisive and impartial scrutiny respects consensus:

Theorem HM1 (Holzman and Moulin 2013) ${ }^{34}$ For the Gregorian format, no decisive, impartial scrutiny satisfies positive unanimity and negative unanimity.

\footnotetext{
32 A question related to selecting two finalists is analyzed by Amorós (2013), who considers the problem of designing a mechanism for a biased jury to select a fixed number of winning contestants. In that setting, however, the jurors and contestants are different people.

33 The longest conclave, which elected Gregory X, lasted from November 1268 to September 1271.

34 This is Theorem 4 in Holzman and Moulin (2013).
} 
When our model is interpreted as the assignment of a single indivisible object among agents who selfishly desire it and black smoke is interpreted as the destruction of that object, the requirement that someone be selected is equivalent to standard efficiency. For this reason, the finding that these axioms become compatible when it is possible to select nobody through black smoke - as evidenced by, for example, the supermajority class-reinforces the finding in various economic models that certain objectives can be achieved only by relaxing efficiency or destroying goods. ${ }^{35}$ Moreover, this complements the finding that the axioms are compatible when selecting multiple winners is possible. ${ }^{36}$ In related work, Bjelde et al. (2017) consider $k$ prizes to be awarded using approval ballots, both when they must all be assigned and when this is not necessary, but instead of proceeding axiomatically they investigate rules that perform well according to the metric introduced in Fischer and Klimm (2014).

Second, no decisive and impartial secret ballot uses the nominations at all:

Theorem HM2 (Holzman and Moulin 2013) ${ }^{37}$ For the Gregorian format, a decisive, impartial scrutiny satisfies anonymous ballots if and only if it is a fixed-winner scrutiny.

This is similar to Theorem 1; it becomes possible to use nominations by allowing the use of black smoke, but this possibility vanishes if self-nomination is then allowed.

To state the third result, we introduce a class of scrutinies, each indexed by an elector who alone determines the winner:

DICTATOR SCRUTINY WITH INDEX $i$ : For each $x \in B$,

$$
\varphi(x)=x_{i}
$$

The third result is that the only decisive and impartial scrutinies that treat electors symmetrically as candidates are the dictator scrutinies:

Theorem M1 (Mackenzie 2015) ${ }^{38}$ For the Gregorian format, a decisive, impartial scrutiny satisfies candidate neutrality if and only if it is a dictator scrutiny.

Though this is a negative result, it is not as negative as Theorem 1 for the Piusine format: there, the dictator rules are no longer impartial even when black smoke is available.

\footnotetext{
35 For example, when money may be transferred and agents have quasi-linear preferences with respect to money, the Groves mechanisms (Vickrey 1961; Clarke 1971; Groves 1973) are the only strategy-proof and partially efficient mechanisms if the domain of admissible valuation function profiles is smoothly connected (Holmström 1979), and these mechanisms necessarily burn money when all valuation functions are admissible (Green and Laffont 1979). In the special case that one object is to be allocated, Sprumont (2013) argues for sometimes destroying the object instead of burning money to distribute surplus more evenly. Other findings along these lines include that an auctioneer seeking to maximize his expected revenue should set a reservation price when buyer valuations are uncertain (Myerson 1981), and that discarding redundant goods without sacrificing efficiency leads to a rich class of desirable rules in classical exchange economies when agents have Leontief preferences ( $\mathrm{Li}$ and Xue 2013).

36 In particular, the axioms are compatible whenever there are $k$ prizes, where $n \geq k>1$ (Tamura 2016). When there are $n$ prizes, the plurality with runners-up rule (Tamura and Ohseto 2014) meets the requirements, provided there are at least four agents, and this rule even has a characterization in terms of other axioms (Tamura 2016).

37 This is Theorem 3 in Holzman and Moulin (2013).

38 This is Corollary 3.3 in Mackenzie (2015).
} 
Taken together, these three findings suggest that there is no acceptable way to use a decisive scrutiny to determine a winner. We therefore broaden our approach to allow for randomization.

Formally, let us say that a chance-scrutiny is a mapping $\varphi: B \rightarrow \Delta(N)$ that associates each ballot profile with a randomization over the electors; the black smoke cannot be used. Each axiom has a natural analogous definition; for formal statements see Mackenzie (2015).

With randomization, the uniform random dictatorship is characterized by some of our axioms. This chance-scrutiny can be simply described as follows: first, have each elector write the name of his nominee onto a card; second, mix these cards in a bowl; third, select one of the cards uniformly at random; finally, the name on that card is the winner. This is, in fact, the only impartial secret ballot chance-scrutiny for which an un-nominated elector never wins:

Theorem M2 (Mackenzie 2015) ${ }^{39}$ An impartial chance-scrutiny satisfies anonymous ballots and negative unanimity if and only if it is uniform random dictatorship.

There are several potential criticisms of this method. We discuss and respond to three.

- The pope may not have the support of two-thirds of the electors. This can possibly be addressed through ceremony. As a proposal, have each elector seal his nomination card before it is cast. After the winning card is selected, but before it is opened, all of the other cards are burned. At this point, each and every elector swears a holy oath to recognize as pope the man whose name is written on the remaining card-that is, the required $\frac{2}{3} n$ of supporters are gathered after the electors vote, but before the outcome is revealed. Finally, the card is opened to reveal the pope.

- An elector nominated by all his peers may not win. There is indeed a small chance that instead, the winner will be the nominee of that elector. This is not a practical concern, as this final method would only be used in a greatly divided conclave. But if the process is interpreted as the electors nominating candidates for God to choose, then this simply means that God always has a choice.

- A pope has never been selected randomly. While this is true to our knowledge, there is in fact precedent for randomization in the assignment of extremely important positions-one must just go back millennia. As reported in Acts 1:12-26, Saint Peter participates in prayer when randomization is used to select the apostle to replace Judas. The excerpt on randomization, from the King James Version of the Bible:

23 And they appointed [nominated] two, Joseph called Barsabas, who was surnamed Justus, and Matthias. ${ }^{24}$ And they prayed, and said, Thou, Lord, which knowest the hearts of all men, shew whether of these two thou hast chosen, ${ }^{25}$ That he may take part of this ministry and apostleship, from which Judas by transgression fell, that he might go to his own place. ${ }^{26}$ And they gave forth their lots; and the lot fell upon Matthias; and he was numbered with the eleven apostles.

There are many other ways deadlock could be handled using randomization-for example, a cardinal could be selected uniformly at random, or scrutiny could narrow

39 This is Corollary 3.4 in Mackenzie (2015). 
the candidates down to two finalists and then one of the nominations for them could be randomly selected. Deadlock could also be handled without randomization-for example, the pope could designate who his successor should be if the electors cannot reach a consensus. We simply raise some concerns with the current method and argue that randomization merits consideration.

\section{Conclusion}

We conclude with a discussion of several additional topics.

WHY PRECISELY TWO- THIRDS OF THE ELECTORS?

We characterize the supermajority class, not the $\frac{2}{3} n$ threshold in particular. Does this particular threshold have any merit outside of its long tradition? Remarkably, similar thresholds have been identified in various problems of social choice-in both finite and infinite settings, from both non-cooperative and cooperative perspectives. We highlight two particularly interesting examples.

First, consider a finite set of voters $N$ and a finite set of candidates $X$. A social choice correspondence associates each profile of voter rankings with a collection of candidates, and its unequivocal majority (if it exists) is the minimum number $n^{*}$ such that at each profile where at least $n^{*}$ agents share a top alternative, that top alternative is uniquely selected. When there are at least three voters and candidates, the minimum unequivocal majority of a social choice correspondence that can be implemented in Nash equilibrium must exceed, but can be arbitrarily close to, $\frac{2}{3} n$ (Amorós 2009). In the context of the papal conclave: under the pessimistic view that each elector behaves strategically according to a fixed ranking of the candidates, the only normative objectives that can be Nash-implemented-through any format of conclave-can come arbitrarily close to, but ultimately fall short of, the decree of the Third Lateran Council that two-thirds of the electors can select the pope.

Second, consider a continuum of voters $N$, a compact set in Euclidean issue space of candidates $X$ (whose dimensions are interpreted as issues), and a fixed profile of voter preferences over $X$. Associate each supermajority threshold $t$ with a cooperative game as follows: if $|S| \geq t$, then $S$ can achieve any alternative; else $S$ can achieve nothing. For which $t$ is the core nonempty? When preferences are Euclidean and the distribution of peaks over $X$ is concave, then a threshold of at least $1-\frac{1}{e}$, or about $63.2 \%$, guarantees a nonempty core regardless of the number of issues (Caplin and Nalebuff 1988). In fact, this is true more generally, provided preferences are appropriately separable across issues and the distribution appropriately rules out heavy polarization (Caplin and Nalebuff 1991). In the context of the papal conclave: the $\frac{2}{3} n$ threshold dates back to an era where the priority was protecting the church from schism, which might occur if a coalition of electors attempts to block an elected pope by crowning their own antipope - that is, precisely in the event of instability. Though this theoretical result applies to an infinite model and the connection is only suggestive, it is interesting that the church's threshold is only slightly above the theoretical minimum required to promise that stability is possible. 


\section{BALLOTS WITHOUT SIGNATURES}

Though a secret ballot was used for over three centuries, nevertheless the physical ballots featured concealed signatures to enforce the prohibition against selfnomination. These signatures would be revealed in rare cases, and if this were a concern, other methods of enforcement could be pursued. We make two such proposals, one involving more paperwork and one involving less.

First, ${ }^{40}$ suppose there are $n$ electors. Before scrutiny, $n$ identical decks of cards are printed and packaged. Each deck consists of $n$ distinct cards, each bearing the name of an elector. To ensure the decks are printed as specified, they are placed in a large bowl and mixed. Each elector takes one deck at random, finds his own card, and finds the card of his nominee. When he votes, he shows his own card and discards it, then secretly casts his nominee's card as his vote, then secretly discards the rest of his cards. To allow electors to vote for non-electors, each deck might also include a single blank card, onto which can be hand-written the name of any non-elector. This handwritten card need not be signed; it can simply be verified that no handwritten cards nominate electors when the cards are counted.

Second, ${ }^{41}$ to enforce the prohibition of self-nomination with less paperwork: use the Piusine ballot format, and in the event that an elector $i$ receives precisely $\frac{2}{3} n$ nominations, there is immediately another vote where each of the other $n-1$ electors writes "Yes" to indicate that he did nominate $i$ or "No" to indicate that he did not; $i$ is then elected if and only if there are at least $\frac{2}{3} n$ "Yes" votes. Clearly, this second vote satisfies impartiality and anonymous ballots. Ultimately, the trade-off is that while this enforcement method involves less paperwork, it relies critically on the honesty of the electors in the follow-up vote.

\section{FUTURE DIRECTIONS}

A few other articles analyze papal elections using the tools of economic theory. Colomer and McLean (1998) use results in social choice theory to explain some of the changes in papal elections throughout history, emphasizing the use of approval voting, and moreover include a particular strong collection of primary sources. Kóczy and Sziklai (2015) consider the 2013 conclave and calculate the Shapley-Shubik index of each elector in a simple game whose winning coalitions are based on where the electors were born and how conservative they are by a particular measure; they find that the winner, known today as Pope Francis, ranks third.

In this article, our analysis has focused on scrutiny when each elector nominates one person, but there are other formats that could be considered. Moreover, we have not attempted to model the evolution of opinions due to observing inconclusive scrutiny results, praying, and communicating with peers. These are interesting topics for future research.

Open Access This article is distributed under the terms of the Creative Commons Attribution 4.0 International License (http://creativecommons.org/licenses/by/4.0/), which permits unrestricted use, distribution, and reproduction in any medium, provided you give appropriate credit to the original author(s) and the source, provide a link to the Creative Commons license, and indicate if changes were made.

\footnotetext{
40 This proposal is a slight adaptation of a proposal of Olga Gorelkina.

41 This proposal was suggested to me by an anonymous referee.
} 


\section{Appendix A}

In this appendix, we prove Theorem 1. Because the proof is closely related to existing proofs in the literature, we first discuss these relationships for the interested reader; we then provide a self-contained proof that does not rely on the discussion.

Structurally, the proof of Theorem 1 consists of two distinct proofs: one for anonymous ballots and one for candidate neutrality. Each of these proofs involves establishing the Piusine analogue of a corresponding result for the Gregorian format without black smoke that already appears in the literature:

Lemma HM1 (Holzman and Moulin 2013) ${ }^{42}$ For the Gregorian format, if $\varphi$ is a decisive, impartial scrutiny satisfying anonymous ballots, then for each $i \in N$ and each pair $x, x^{\prime} \in B$ such that $\mathcal{S}_{i}(x)=\mathcal{S}_{i}\left(x^{\prime}\right)$,

$$
\varphi(x)=i \text { if and only if } \varphi\left(x^{\prime}\right)=i \text {. }
$$

LEMMA M (Mackenzie 2015) ${ }^{43}$ For the Gregorian format, if $\varphi$ is a decisive, impartial scrutiny satisfying candidate neutrality, then for each $N^{\prime} \subseteq N$, either

- for each $i \in N$ and each $x \in B,\left\{j \in N \mid x_{j}=i\right\}=N^{\prime}$ implies $\varphi(x)=i$; or

- for each $i \in N$ and each $x \in B,\left\{j \in N \mid x_{j}=i\right\}=N^{\prime}$ implies $\varphi(x) \neq i$.

The first lemma provides conditions under which each elector's outcome is determined by his score, while the second lemma provides conditions under which each coalition has a fixed outcome that it imparts to any nominee. Both of these lemmas in fact have identical proofs when black smoke is introduced; in other words, decisiveness can safely be dropped from the above lemmas.

When we move to the Piusine format, the analogous conclusions are logically stronger because there are more ballot profiles, but the hypotheses are also logically stronger for the same reason, and overall the proofs become simpler. Instead of supporting this claim with informal arguments, we instead illustrate it formally in the proof below by using simpler constructive arguments than are available in the Gregorian setting:

Theorem 1 For the Piusine format with at least two electors, an impartial scrutiny satisfies

- anonymous ballots if and only if it is a fixed-winner scrutiny or the black smoke scrutiny, and

- candidate neutrality if and only if it is the black smoke scrutiny.

Proof We prove the parts in sequence, omitting the straightforward verification of the axioms. It is convenient to introduce an indicator for whether or not a particular elector wins at a particular ballot profile; for each $i \in N$ and each $x \in B$, define

$$
\varphi_{i}(x) \equiv \begin{cases}1, & \varphi(x)=i \\ 0, & \text { else }\end{cases}
$$

\footnotetext{
42 This result is established in the proof of Theorem 3 in Holzman and Moulin (2013).

43 This is an immediate corollary of Lemma 2.2 in Mackenzie (2015), which more generally applies when the scrutiny's outcome may involve randomization.
} 
- STEP 1: Assume $\varphi$ satisfies impartiality and anonymous ballots.

It is straightforward to show that the set of score profiles $S$ is

$$
S=\left\{s \in\{0,1, \ldots, n\}^{N} \mid \sum s_{k}=n\right\}
$$

It is an immediate consequence of anonymous ballots that for each $s \in S$, we can write $\varphi(s)$ to denote the outcome $\varphi(x)$ of any profile $x$ such that $\mathcal{S}(x)=s$.

CLAIM: Each elector's outcome is determined by his own score.

Proof of claim: Let $i \in N$, let $v \in\{0,1, \ldots, n\}$, and define $S_{i, v}$ to be the collection of score profiles where $i$ receives score $v$,

$$
S_{i, v} \equiv\left\{s \in S \mid s_{i}=v\right\}
$$

Let us say that two score profiles $s, s^{\prime} \in S_{i, v}$ are adjacent if there are $j, j^{\prime} \in N$ such that $s^{\prime}$ is obtained from $s$ by transferring one nomination from $j$ to $j^{\prime}$; that is, if (i) $s_{j}^{\prime}=s_{j}-1$; (ii) $s_{j^{\prime}}^{\prime}=s_{j^{\prime}}+1$; and (iii) for each $k \in N \backslash\left\{j, j^{\prime}\right\}, s_{k}^{\prime}=s_{k}$.

Within this claim, we make the sub-claim that any two adjacent score profiles in $S_{i, v}$ are assigned the same outcome by $\varphi$. Indeed, let $s, s^{\prime} \in S_{i, v}$ be adjacent. Then, there are $j, j^{\prime} \in N$ such that $s^{\prime}$ is obtained from $s$ by transferring one nomination from $j$ to $j^{\prime}$. Construct $x \in B$ such that $\mathcal{S}(x)=s$ and $x_{i}=j$ as follows: (i) initialize each elector's partial score to zero, and at the end of each step increase the partial score of the nominee in the newly defined nomination by one; (ii) in the first step, define $x_{i} \equiv j$; (iii) iteratively take the least-index elector whose nomination has not yet been defined, and define his nominee to be the least-index elector whose partial score is below his score at $s$. Define $x^{\prime} \in B$ such that $\mathcal{S}\left(x^{\prime}\right)=s^{\prime}$ and $x_{i}=j^{\prime}$ as follows: (i) $x_{i}^{\prime}=j^{\prime}$; and (ii) for each $k \in N \backslash\{i\}, x_{k}^{\prime}=x_{k}$. By impartiality, $\varphi_{i}(x)=\varphi_{i}\left(x^{\prime}\right)$; thus $\varphi(s)=\varphi\left(s^{\prime}\right)$, as desired.

To complete the proof of the claim, let $s, s^{\prime} \in S_{i, v}$. For each $L \in \mathbb{N}$, a path from $s$ to $s^{\prime}$ of length $L$ is an ordered list of score profiles $\left(s^{1}, s^{2}, \ldots, s^{L}\right) \in S_{i, v}^{L}$ such that (i) $s^{1}=s$; (ii) $s^{L}=s^{\prime}$; and (iii) for each $t \in\{1,2, \ldots, L-1\}, s^{t}$ and $s^{t+1}$ are adjacent. To construct a path between $s$ and $s^{\prime}$ of some length $L$, we can simply begin at $s$, and at each step both (i) remove one nomination for the least-index elector whose score exceeds his score at $s^{\prime}$ and (ii) add one nomination for the least-index elector whose score is below his score at $s^{\prime} ; L$ is simply the number of score profiles generated by this algorithm. By the sub-claim, $\varphi(s)=\varphi\left(s^{1}\right)=\varphi\left(s^{2}\right)=\ldots=\varphi\left(s^{L}\right)=\varphi\left(s^{\prime}\right)$. Since $s, s^{\prime} \in S_{i, v}$ were arbitrary, $i$ is assigned the same outcome by $\varphi$ at any profile where his score is $v$. Since $v \in\{0,1, \ldots, n\}$ was arbitrary, $i$ 's outcome is determined by his own score. Since $i \in N$ was arbitrary, we are done.

To conclude, let $i \in N$. By the above claim, $i$ 's outcome is determined by his score; thus there is $V_{i} \subseteq\{0,1, \ldots, n\}$ such that for each $x \in B, \varphi(x)=i$ if and only if $\mathcal{S}_{i}(x) \in V_{i}$.

We claim that $v \in V_{i} \backslash\{n\}$ implies $v+1 \in V_{i}$. Indeed, assume there is $v \in V_{i} \backslash\{n\}$. Let $x \in B$ be such that $\mathcal{S}_{i}(x)=v$ and $x_{i} \neq i$, and define $x^{\prime} \in B$ as follows: (i) $x_{i}^{\prime} \equiv i$; 
and (ii) for each $j \in N \backslash\{i\}, x_{j}^{\prime} \equiv x_{j}$. Then, $\mathcal{S}_{i}(x) \in V_{i}$, so $\varphi(x)=i$, so by impartiality $\varphi\left(x^{\prime}\right)=i$, so $v+1=\mathcal{S}_{i}\left(x^{\prime}\right) \in V_{i}$.

By a similar argument, $v \in V_{i} \backslash\{0\}$ implies $v-1 \in V_{i}$. Altogether, then, either $V_{i}=\emptyset$ or $V_{i}=\{0,1, \ldots, n\}$. Since $i \in N$ was arbitrary, this is true for each elector. There cannot be distinct $i, j \in N$ such that $V_{i}=V_{j}=\{0,1, \ldots, n\}$, else for each $x \in B, i=\varphi(x)=j$, contradicting that $i$ and $j$ are distinct. Because there is at most one $i \in N$ for which $V_{i}=\{0,1, \ldots, n\}$, and because for any other $j \in N, V_{j}=\emptyset$, it follows that $\varphi$ is either a fixed-winner scrutiny or the black smoke scrutiny.

- STEP 2: Assume $\varphi$ satisfies impartiality and candidate neutrality.

For each $x \in B$ and each $i \in N$, define

$$
x_{i}^{-1} \equiv\left\{j \in N \mid x_{j}=i\right\} .
$$

Let $\Pi$ denote the set of partitions of $N$. For each $x \in B$, define the voting partition of $x, \mathcal{P}(x) \in \Pi$, by

$$
\mathcal{P}(x) \equiv\left\{x_{i}^{-1} \mid i \in N\right\} \backslash\{\emptyset\}
$$

It is convenient to introduce notation to add the empty set to any voting partition where necessarily at least one elector is nominated by nobody: for each $\pi \in \Pi$, define the expansion of $\pi, \pi_{\emptyset}$, by

$$
\pi_{\emptyset} \equiv\left\{\begin{array}{lr}
\pi, & |\pi|=n \\
\pi \cup\{\emptyset\}, & \text { else. }
\end{array}\right.
$$

We claim that for each $\pi \in \Pi$ and each $N^{\prime} \in \pi_{\emptyset}$, we can write $\varphi\left(\pi, N^{\prime}\right)$ to denote the outcome that $N^{\prime}$ imparts to any nominee when the voting partition is $\pi$. Indeed, let $\pi \in \Pi$, let $N^{\prime} \in \pi_{\emptyset}$, let $x, x^{\prime} \in B$ such that $\mathcal{P}(x)=\mathcal{P}\left(x^{\prime}\right)=\pi$, let $i \in N$ such that $x_{i}^{-1}=N^{\prime}$, and let $j \in N$ such that $x_{j}^{\prime-1}=N^{\prime}$. Construct permutation $\sigma$ as follows: (i) for each $N^{*} \in \pi$, map the nominee of $N^{*}$ at $x$ to the nominee of $N^{*}$ at $x^{\prime}$; (ii) map $i$ to $j$ if this is not already done (that is, if $N^{\prime}=\emptyset$ ); and (iii) iteratively map the least-index un-mapped elector to the least-index elector who has not yet been mapped to. We show that $\varphi_{j}\left(x^{\prime}\right)=\varphi_{i}(x)$ in three collectively exhaustive (but not mutually exclusive) cases:

(i) if $\varphi(x) \in N$, then by candidate neutrality, $\varphi\left(x^{\prime}\right)=\varphi\left(x^{\mathbb{1}, \sigma}\right)=\sigma(\varphi(x))$, so $\varphi_{j}\left(x^{\prime}\right)=\varphi_{\sigma(i)}\left(x^{\prime}\right)=\varphi_{i}(x)$;

(ii) if $\varphi\left(x^{\prime}\right) \in N$, then as $x=x^{\prime 11, \sigma^{-1}}$, we can apply an argument that is symmetric to that of the previous case; and

(iii) if $\varphi(x) \notin N$ and $\varphi\left(x^{\prime}\right) \notin N$, then $\varphi_{j}\left(x^{\prime}\right)=\varphi_{i}(x)$.

Since $x, x^{\prime} \in B$ were arbitrary ballot profiles with voting partition $\pi, i$ was an arbitrary agent with $x_{i}^{-1}=N^{\prime}$, and $j$ was an arbitrary agent with $x_{j}^{\prime-1}=N^{\prime}$, thus $N^{\prime}$ imparts the same outcome to any nominee when the voting partition is $\pi$. Since $\pi \in \Pi$ and $N^{\prime} \in \pi_{\emptyset}$ were arbitrary, we are done.

CLAIM: Each coalition has a fixed outcome that it imparts to any nominee. 
Proof of claim: Let $N_{0} \subseteq N$, and define $\Pi_{N_{0}}$ to be the set of partitions of $N$ whose expansions include $N_{0}$,

$$
\Pi_{N_{0}} \equiv\left\{\pi \in \Pi \mid N_{0} \in \pi_{\emptyset}\right\}
$$

Let us say two distinct partitions $\pi, \pi^{\prime} \in \Pi_{N_{0}}$ are adjacent if there are $i_{0} \in N \backslash N_{0}$ and disjoint $N_{1}, N_{2} \subseteq N \backslash N_{0}$ such that

(i) $\pi_{\emptyset}=\left(\pi \cap \pi^{\prime}\right) \cup\left\{N_{1} \cup\left\{i_{0}\right\}, N_{2}\right\}$, and

(ii) $\pi_{\emptyset}^{\prime}=\left(\pi \cap \pi^{\prime}\right) \cup\left\{N_{1}, N_{2} \cup\left\{i_{0}\right\}\right\}$.

Loosely, $\pi$ and $\pi^{\prime}$ are adjacent if one is obtained from the other when a single elector moves from one coalition to another. The coalition this elector leaves behind may be empty, as may the coalition this elector joins, although they cannot both be (else $\left.\pi=\pi^{\prime}\right)$.

Within this claim, we make the sub-claim that any two adjacent partitions in $\Pi_{N_{0}}$ provide the same outcome to the nominee of $N_{0}$. Indeed, let $\pi, \pi^{\prime} \in \Pi_{N_{0}}$ be adjacent. Then, there are $i_{0} \in N$ and disjoint $N_{1}, N_{2} \subseteq N$ such that $\pi^{\prime}$ is obtained from $\pi$ when $i_{0}$ leaves $N_{1}$ and joins $N_{2}$. As discussed above, it cannot be that $N_{1}$ and $N_{2}$ are both empty; thus let us assume, without loss of generality, that $N_{2} \neq \emptyset$. Construct $x \in B$ such that $\mathcal{P}(x)=\pi$ as follows: (i) for each $N^{*} \in \pi \backslash\left\{N_{0}, N_{1} \cup\left\{i_{0}\right\}\right\}$ and each $k \in N^{*}$, define $x_{k} \equiv \min N^{*}$; (ii) for each $k \in N_{0}$, define $x_{k} \equiv i_{0}$; and (iii) for each $k \in N_{1} \cup\left\{i_{0}\right\}$, define $x_{k}$ to be the least-index elector in $N \backslash\left\{i_{0}\right\}$ who was not nominated in the first two steps. Define $x^{\prime} \in B$ such that $\mathcal{P}\left(x^{\prime}\right)=x^{\prime}$ as follows: (i) $x_{i_{0}}^{\prime}=\min N_{2}$; and (ii) for each $k \in N \backslash\{i\}, x_{k}^{\prime}=x_{k}$. By impartiality, $\varphi_{i_{0}}(x)=\varphi_{i_{0}}\left(x^{\prime}\right)$; thus $\varphi\left(\pi, N_{0}\right)=\varphi\left(\pi^{\prime}, N_{0}\right)$, as desired.

To complete the proof of the claim, let $\pi, \pi^{\prime} \in \Pi_{N_{0}}$. For each $L \in \mathbb{N}$, a path from $\pi$ to $\pi^{\prime}$ of length $L$ is an ordered list of partitions $\left(\pi^{1}, \pi^{2}, \ldots, \pi^{L}\right) \in \Pi_{N_{0}}^{L}$ such that (i) $\pi^{1}=\pi$; (ii) $\pi^{L}=\pi^{\prime}$; and (iii) for each $t \in\{1,2, \ldots, L-1\}, \pi^{t}$ and $\pi^{t+1}$ are adjacent. To construct a path between $\pi$ and $\pi^{\prime}$ of some length $L$, we can simply begin at $\pi$, at each step consider the least-index elector whose set is not as in $\pi^{\prime}$, and either (i) bring in the least-index elector missing from his set in $\pi^{\prime}$; or (ii) if there is no such elector, remove the least-index elector who is not in his set in $\pi^{\prime}$ and put this elector in his own group; $L$ is simply the number of partitions generated by this algorithm. ${ }^{44}$ By the sub-claim, $\varphi\left(\pi, N_{0}\right)=\varphi\left(\pi^{1}, N_{0}\right)=\varphi\left(\pi^{2}, N_{0}\right)=\ldots=\varphi\left(\pi^{L}, N_{0}\right)=\varphi\left(\pi^{\prime}, N_{0}\right)$. Since $\pi, \pi^{\prime} \in \Pi_{N_{0}}$ were arbitrary, thus $N_{0}$ has a fixed outcome it imparts to any nominee. Since $N_{0} \subseteq N$ was arbitrary, we are done.

To conclude: by the above claim, each coalition has a fixed outcome that it imparts to any nominee; thus there is $\mathcal{D} \subseteq 2^{N}$ such that for each $i \in N$ and each $x \in B$, $\varphi(x)=i$ if and only if $x_{i}^{-1} \in \mathcal{D}$.

We claim that if there is $D \in \mathcal{D}$, then $\emptyset \in \mathcal{D}$. Indeed, assume there is nonempty $D \in \mathcal{D}$, let $i \in D$, let $j \in N \backslash\{i\}$, and define $x \in B$ as follows: (i) for each $k \in D$, $x_{k} \equiv i$; and (ii) for each $k \in N \backslash D, x_{k} \equiv j$. Define $x^{\prime} \in B$ as follows: (i) $x_{i}^{\prime} \equiv j$;

\footnotetext{
44 Of course, this algorithm need not generate the shortest path between the two partitions. The length of the shortest path between two partitions was introduced by Régnier (1965) as a measure of the distance between them.
} 
and (ii) for each $k \in N \backslash\{i\}, x_{k}^{\prime} \equiv x_{k}$. Then, $x_{i}^{-1} \in \mathcal{D}$, so $\varphi(x)=i$, so by impartiality $\varphi\left(x^{\prime}\right)=i$, so $D \backslash\{i\}=x_{i}^{\prime-1} \in \mathcal{D}$. Since nonempty $D \in \mathcal{D}$ and $i \in D$ were arbitrary, it follows that $\emptyset \in \mathcal{D}$.

Assume, by way of contradiction, there is $x \in B$ such that $\varphi(x) \neq 0$. Then, $x_{\varphi(x)}^{-1} \in \mathcal{D}$, so by the above argument $\emptyset \in \mathcal{D}$. If $n=2$, then (i) 1 wins when both nominate 2 , so by impartiality 1 wins when each nominates himself; and (ii) 2 wins when both nominate 1 , so by impartiality 2 wins when each nominates himself; this contradicts that $1 \neq 2$. If $n \geq 3$, then let $i, j, k \in N$ be distinct, and let $x \in B$ be the profile where each elector designates $i$. Since $x_{j}^{-1}=x_{k}^{-1}=\varnothing \in \mathcal{D}$, thus $j=\varphi(x)=k$, contradicting that $j$ and $k$ are distinct. Thus in both cases, $\varphi$ is the black smoke scrutiny.

\section{Appendix B}

In this appendix, we prove Proposition 2.1, Proposition 2.2, and Theorem 2. The following lemma simplifies our analysis:

Lemma HM2 (Holzman and Moulin 2013) For the Gregorian format, if $\varphi$ is an impartial scrutiny satisfying anonymous ballots, then for each $i \in N$ and each pair $x, x^{\prime} \in B$ such that $\mathcal{S}_{i}(x)=\mathcal{S}_{i}\left(x^{\prime}\right)$,

$$
\varphi(x)=i \text { if and only if } \varphi\left(x^{\prime}\right)=i \text {. }
$$

As discussed in Appendix A, the proof of the above lemma is identical to the proof of Lemma HM1, which appears in the proof of Theorem 3 in Holzman and Moulin (2013) for the Gregorian setting without black smoke, and which furthermore has some suppressed details shown explicitly when it is adapted to allow for randomization in the proof of Lemma 1.2 in Mackenzie (2015). We therefore omit the formal proof, but describe it informally in Fig. 2.

The first proposition involves the following class of scrutinies, which includes the black smoke scrutiny:

RESTRICTED UNANIMITY SCRUTINY INDEXED BY $N^{\prime} \subsetneq N$ : An elector wins if and only if he is in $N^{\prime}$ and he is nominated by all his peers.

In particular, the first proposition characterizes the class of scrutinies satisfying impartiality, monotonicity, and two of our symmetry axioms:

Proposition 2.1 For the Gregorian format with at least three electors, an impartial scrutiny satisfies monotonicity, anonymous ballots, and candidate neutrality if and only if it is a supermajority scrutiny or a restricted unanimity scrutiny.

Proof We omit the straightforward verification of axioms. 


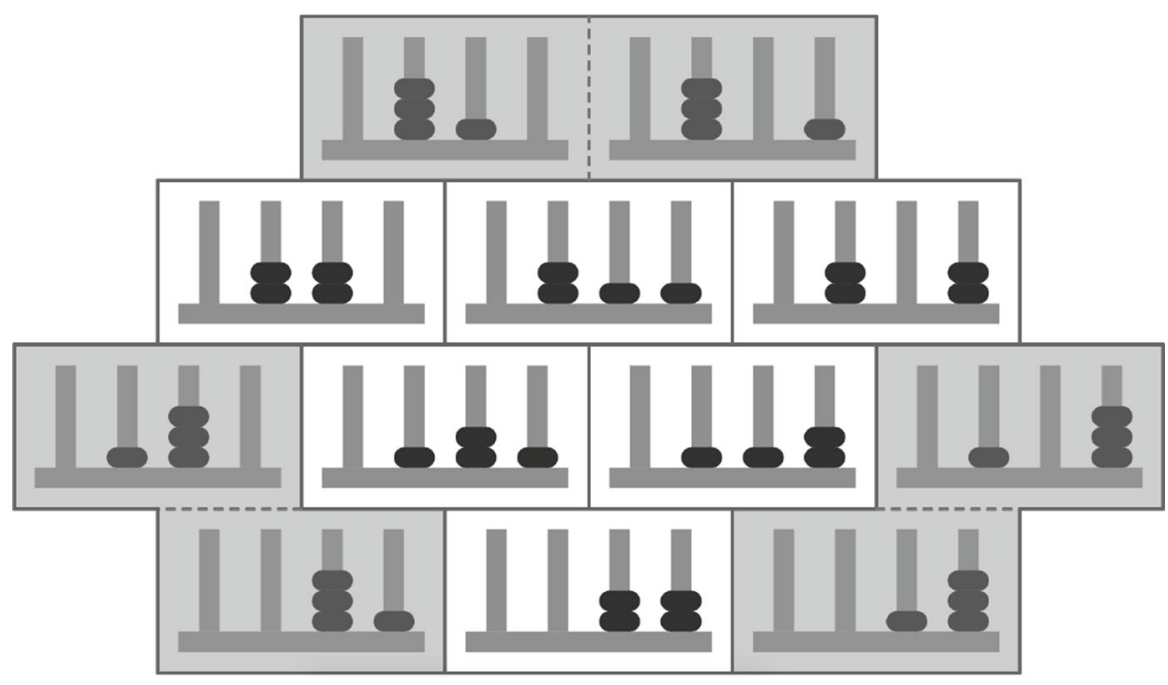

Fig. 2 The omitted proof of Lemma HM2 (Holzman and Moulin 2013). For illustration, there are four electors. Each box shows a score profile, with the number of disks on the $i$ th pole from the left showing the score of $i$. Using our notation from the proof of Theorem 1, the boxes together show $S_{1,0}$ - the set of score profiles where elector 1 has score 0 - but the argument applies for any elector $i$, any score $v$, and any $S_{i, v}$. Any two boxes that touch have adjacent score profiles. Though elector 1 could never move between two adjacent score profiles whose boxes are both shaded by changing his nomination, he could move between any other pair of adjacent score profiles; this can be proved using a generalization of Hall's Marriage Lemma (Hall 1935) that appears in (Wilson 1972). Thus by impartiality, the given elector has the same outcome whenever he has the given score. For details, see the proof of Lemma 1.2 in Mackenzie (2015)

Assume that $\varphi$ satisfies the axioms. By Lemma HM2, each elector's outcome is determined by his score; thus for each $i \in N$, there is $V_{i} \subseteq\{0,1, \ldots, n-1\}$ such that $\varphi(x)=i$ if and only if $\mathcal{S}_{i}(x) \in V_{i}$.

CASE 1: There is $i \in N$ such that $V_{i} \backslash\{n-1\} \neq \emptyset$. Define $v \equiv \min V_{i}$; note that $v \leq n-2$. Let $j \in N \backslash\{i\}$, and let $N^{\prime} \subseteq N \backslash\{i, j\}$ such that $\left|N^{\prime}\right|=v$. Define $x \in B$ as follows: (i) for each $k \in N^{\prime}, x_{k} \equiv i$; (ii) for each $k \in N \backslash\left(N^{\prime} \cup\{i, j\}\right), x_{k} \equiv j$; and (iii) $x_{i}=x_{j} \equiv \min N \backslash\{i, j\}$. Let $\sigma$ be the transposition of $i$ and $j$, and define $x^{\prime} \in B$ as follows: for each $k \in N, x_{k}^{\prime} \equiv \sigma\left(x_{k}\right)$. Then, $\mathcal{S}_{i}(x) \in V_{i}$, so $\varphi(x)=i$, so by candidate neutrality $\varphi\left(x^{\prime}\right)=j$, so $v=\mathcal{S}_{j}(x) \in V_{j}$.

Since $i \in N$ with $V_{i} \backslash\{n-1\} \neq \varnothing$ and $j \in N \backslash\{i\}$ were arbitrary, thus for each pair $i, j \in N, \min V_{i}=\min V_{j}$. By monotonicity, there is $v^{*} \in\{0,1, \ldots, n-1\}$ such that for each $i \in N, V_{i}=\left\{v^{*}, v^{*}+1, \ldots, n-1\right\}$. It cannot be that $v^{*} \leq \frac{n}{2}$, else at any profile where two electors have score $v^{*}$, both of those electors would be selected, which is impossible. Thus, $\varphi$ is a supermajority scrutiny.

CASE 2: For each $i \in N, V_{i} \backslash\{n-1\}=\emptyset$. Then, it is immediate that $\varphi$ is either (i) a restricted unanimity scrutiny, or (ii) the supermajority scrutiny with index $n-1$.

Our second proposition provides the analogous characterizations for the other two pairs of symmetry axioms: 
Proposition 2.2 For the Gregorian format with at least three electors, the following are equivalent:

- $\varphi$ is either a supermajority scrutiny or the black smoke scrutiny;

- $\varphi$ satisfies impartiality, monotonicity, anonymous ballots, and name independence;

- $\varphi$ satisfies impartiality, monotonicity, candidate neutrality, and name independence.

Proof This is immediate from Proposition 2.1, since for the Gregorian format, (i) anonymous ballots and name independence imply candidate neutrality, and (ii) candidate neutrality and name independence imply anonymous ballots.

Finally, Theorem 2 provides the three associated characterizations when positive unanimity is added to the list of requirements, and moreover states that each of these characterizations is tight when there are sufficiently many electors:

Theorem 2 For the Gregorian format with at least three electors, the following are equivalent:

- $\varphi$ is a supermajority scrutiny;

- $\varphi$ satisfies impartiality, monotonicity, positive unanimity, anonymous ballots, and candidate neutrality;

- $\varphi$ satisfies impartiality, monotonicity, positive unanimity, anonymous ballots, and name independence;

- $\varphi$ satisfies impartiality, monotonicity, positive unanimity, candidate neutrality, and name independence.

Moreover, if there are at least seven electors, then each of these three characterizations is tight.

Proof The characterizations are immediate from Proposition 2.1 and Proposition 2.2, since each restricted unanimity scrutiny (including the black smoke scrutiny) violates positive unanimity.

To establish tightness of the three characterizations, we provide, for each characterization and each axiom in that characterization, an example of a scrutiny satisfying the other axioms in that characterization that is not a supermajority scrutiny. In addition to the scrutinies defined in Sect. 3, we introduce the following, favoring plain language over mathematical formality for clarity:

ACCLAIM UNLESS A TWICE- DESIGNATED PEER: An elector wins if and only if he is nominated by at least $n-2$ peers and none of his peers is nominated twice.

MAJORITY UNLESS ONE DISSENTER: An elector wins if and only if he is nominated by over half his peers and not by $n-2$ peers.

WEIGHTED MAJORITY SCRUTINY INDEXED BY $\left(w_{i}\right)$ : Elector $i$ wins if and only if

$$
\sum_{\left\{j \in N \mid x_{j}=i\right\}} w_{j}>\frac{\sum w_{j}}{2} .
$$


PeRsonAlized THRESHOLD SCRUTINY INDEXED BY $\left(v_{i}\right)$, min $v_{i}+v_{j}>n$ : Elector $i$ wins if and only if he receives at least $v_{i}$ nominations.

MAJORITY WITHOUT MULTIPLE PEER- NOMINATED OPPONENTS: Elector $i$ wins if and only if (i) he receives over $\frac{n}{2}$ nominations, and (ii) there is at most one other elector who is nominated by one of $i$ 's peers.

These examples apply across the three characterizations:

- impartiality: Acclaim unless a twice-designated peer, provided there are at least four electors.

- monotonicity: Majority unless one dissenter, provided there are at least seven electors.

- positive unanimity: Black smoke scrutiny, provided there are at least two electors.

For the first characterization:

- anonymous ballots: Weighted majority, provided there are at least four electors.

- candidate neutrality: Personalized threshold scrutiny, provided there are at least four electors.

For the second characterization:

- anonymous ballots: Majority without multiple peer-nominated opponents, provided there are at least seven electors.

- name independence: Personalized threshold scrutiny, provided there are at least four electors.

For the third characterization:

- candidate neutrality: Majority without multiple peer-nominated opponents, provided there are at least seven electors.

- name independence: Weighted majority, provided there are at least four electors.

\section{References}

\section{Economic literature}

Abdulkadiroğlu, A., Sönmez, T.: House allocation with existing tenants. J. Econ. Theory 88, 233-260 (1999)

Abdulkadiroğlu, A., Sönmez, T.: School choice: a mechanism design approach. Am. Econ. Rev. 93, 729-747 (2003)

Amorós, P.: Unequivocal majority and Maskin-monotonicity. Soc. Choice Welf. 33, 521-532 (2009)

Amorós, P.: Picking the winners. Int. J. Game Theory 42, 845-865 (2013)

Aumann, R., Maschler, M.: Game theoretic analysis of a bankruptcy problem from the Talmud. J. Econ. Theory 36, 195-213 (1985)

Balinski, M., Sönmez, T.: A tale of two mechanisms: student placement. J. Econ. Theory 84, 73-94 (1999) Bjelde, A., Fischer, F., Klimm, M.: Impartial selection and the power of up to two choices. ACM Trans. Econ. Comput. (TEAC) 5, Article Number 21 (2017)

Black, D.: On the rationale of group decision-making. J. Polit. Econ. 56, 23-34 (1948)

Caplin, A., Nalebuff, B.: On 64\%-majority rule. Econometrica 56, 787-815 (1988) 
Caplin, A., Nalebuff, B.: Aggregation and social choice: a mean voter theorem. Econometrica 59, 1-23 (1991)

Clarke, E.: Multipart pricing of public goods. Public Choice 8, 19-33 (1971)

Colomer, J., McLean, I.: Electing popes: approval balloting and qualified-majority rule. J. Interdiscip. Hist. 29, 1-22 (1998)

de Clippel, G., Moulin, H., Tideman, N.: Impartial division of a dollar. J. Econ. Theory 139, 176-191 (2008)

Fischer, F., Klimm, M.: Optimal impartial selection. In: Proceedings of the 15th ACM Conference on Economics and Computation, pp. 803-820 . ACM Press, New York (2014)

Gibbard, A.: Manipulation of voting schemes: a general result. Econometrica 41, 587-601 (1973)

Green, J., Laffont, J.: Incentives in Public Decision Making. North Holland Publishing Company, Amsterdam (1979)

Groves, T.: Incentives in teams. Econometrica 41, 617-631 (1973)

Hall, P.: On representatives of subsets. J. Lond. Math. Soc. 10, 26-30 (1935)

Holmström, B.: Groves' scheme on restricted domains. Econometrica 47, 1137-1144 (1979)

Holzman, R., Moulin, H.: Impartial nominations for a prize. Econometrica 81, 173-196 (2013)

Kóczy, L., Sziklai, B.: Electing the pope. Homo Oeconomicus 32, 101-116 (2015)

Li, J., Xue, J.: Egalitarian division under Leontief preferences. Econ. Theory 54, 597-622 (2013). https:// doi.org/10.1007/s00199-012-0724-0

Mackenzie, A.: Symmetry and impartial lotteries. Games Econ. Behav. 94, 15-28 (2015)

May, K.: A set of independent necessary and sufficient conditions for simple majority decision. Econometrica 20, 680-684 (1952)

McLean, I.: The Borda and Condorcet principles: three medieval applications. Soc. Choice Welf. 7, 99-108 (1990)

Mihara, H.: Anonymity and neutrality in Arrow's Theorem with restricted coalition algebras. Soc. Choice Welf. 14, 503-512 (1997)

Myerson, R.: Optimal auction design. Math. Oper. Res. 6, 58-73 (1981)

$\mathrm{Ng}$, Y., Sun, G.: Exclusion of self evaluations in peer ratings: an impossibility and some proposals. Soc. Choice Welf. 20, 443-456 (2003)

O'Neill, B.: A problem of rights arbitration from the Talmud. Math. Soc. Sci. 2, 345-371 (1982)

Régnier, S.: Sur quelques aspects mathématiques des problèmes de classification automatique. ICC [Int. Comput. Centre] Bull. 4, 175-191 (1965)

Roth, A.: Repugnance as a constraint on markets. J. Econ. Perspect. 21, 37-58 (2007)

Roth, A., Sönmez, T., Ünver, M.: Kidney exchange. Q. J. Econ. 119, 457-488 (2004)

Sönmez, T.: Bidding for army career specialties: improving the ROTC branching mechanism. J. Polit. Econ. 121, 186-219 (2013)

Sönmez, T., Switzer, T.: Matching with (branch-of-choice) contracts at the United States Military Academy. Econometrica 81, 451-488 (2013)

Sprumont, Y.: Constrained-optimal strategy-proof assignment: beyond the Groves mechanisms. J. Econ. Theory 148, 1102-1121 (2013)

Suzuki, T., Horita, M.: Impartial nomination rules with a variety of domain-range settings. Working paper (2016)

Tamura, S.: Characterizing minimal impartial rules for awarding prizes. Games Econ. Behav. 95, 41-46 (2016)

Tamura, S.: An impartial and unanimous nomination rule for choosing at most $k$ prize-winners. Working paper (2016)

Tamura, S., Ohseto, S.: Impartial nomination correspondences. Soc. Choice Welf. 43, 47-54 (2014)

Thomson, W.: How to Divide when there Isn't Enough: From Aristotle, the Talmud, and Maimonides to the Axiomatics of Resource Allocation. Forthcoming, Cambridge University Press (2019)

Thomson, W.: Axiomatic and game-theoretic analysis of bankruptcy and taxation problems: an update. Math. Soc. Sci. 74, 41-59 (2015)

Vickrey, W.: Counterspeculation, auctions, and competitive sealed tenders. J. Finance 16, 8-37 (1961)

Wilson, J.: Introduction to Graph Theory. Academic Press, Waltham (1972) 


\section{Historical sources}

Marcellinus, A.: (circa 352). “The Banishment of Liberius.” Res Gestae, XV [Events, Volume 15]. Translation: Shotwell, J., Loomis, L. The See of Peter, p. 633. Columbia University Press, New York (1991)

Pope Alexander III Concilium Lateranense III [Third Lateran Council]. Translation: Tanner, N. (1990). Decrees of the Ecumenical Councils, Volume I: Nicaea I to Lateran V, pp. 204-225. Georgetown University Press, Washington (1179)

Pope Benedict XVI: De aliquibus mutationibus in normis de electione Romani Pontificis [Regarding some changes in norms of the election of the Roman Pontiff]. Apostolic letter issued motu proprio. Acta Apostolicae Sedis 99(9), 776-777 (2007)

Pope Benedict XVI: De nonnullis mutationibus in normis ad electionem Romani Pontificis attinentibus [Regarding some changes in norms to the election standards of the Roman Pontiff]. Apostolic letter issued motu proprio. Acta Apostolicae Sedis 105(3), 253-257. Translation: Vatican website, Libreria Editrice Vaticana (2013)

Pope Celestine I: (428). Epistola III. Caelistini I. papae ad episcopos Illyrici [Epistle 3, Pope Celestine I to the Illyrican bishops]. Epistle. In: Coustant, P. Epistolae Romanorum Pontificum, et quae ad eos scriptae sunt, a S. Clemente I. usque ad Innocentium III. [Epistles of the Roman Pontiffs, and those which were written to them, from Saint Clement I to Innocent III], pp. 1063-1065. Ludovicum-Dionysium Delatour and Antonium-Urbanum Coustelier, Paris. (1721)

Pope Celestine V: Quia in futurorum [For the future]. Papal bull. In: Theiner, A. (1871). Annales Ecclesiastici XXIII [Chuch Records, Volume 23 (Years 1286-1312)]. p. 143. Victorem Palme, Paris (1294)

POPE FELIX IV: (circa 530). Praeceptum papae Felicis morientis per quod sibi Bonifacium archidiaconum suum post se substitutere cupiebat [Command of Pope Felix, where he writes that he wants to substitute Archdeacon Boniface into his post]. In: Duchesne, L. (1883). "La succession du Pape Félix IV." Mélanges d'archéologie et d'histoire 3, 239-266

Pope Gregory X: Ubi periculum [Where risk]. Papal bull. In: Mansi, J. (1780). Sacrorum conciliorum nova et amplissima collectio, XXIV [The new and largest collection of religious councils, Volume 24 (Years 1269-1299)], pp. 81-86. Antonius Zatta, Venice (1274)

Pope Gregory XV: Aeterni Patris [Eternal Father]. Papal bull. In: Cherubini, L. (1692). Magnum Bullarium Romanum, a Clemente VIII usque ad Gregorium XV. [Great Roman Bullarium, from Clement VIII through Gregory XV.], pp. 396-399. Petri Borde, Joannis \& Petri Arnaud, Lugdunum (1621)

Pope Gregory XV: Decet Romanum Pontificem [It suits the Roman Pontiff]. Papal bull. In: Cherubini, L. (1692). Magnum Bullarium Romanum, a Clemente VIII usque ad Gregorium XV. [Great Roman Bullarium, from Clement VIII through Gregory XV.], pp. 405-414. Petri Borde, Joannis \& Petri Arnaud, Lugdunum (1622)

Pope Innocent II: Concilium Lateranense II [Second Lateran Council]. Translation: Tanner, N. (1990). Decrees of the Ecumenical Councils, Volume I: Nicaea I to Lateran V, pp. 195-203. Georgetown University Press, Washington (1139)

Pope John XXIII: Summi Pontificis Electio [The Election of the Supreme Pontiff]. Apostolic letter issued motu proprio. Acta Apostolicae Sedis 54, 632-640 (1962)

Pope John Paul II: Universi Dominici Gregis [The Entire Flock of the Lord. Apostolic constitution. Acta Apostolicae Sedis 88, 305-343. Translation: Vatican website, Libreria Editrice Vaticana (1996)

Pope Nicholas II: (1059). In nomine Domini [In the name of the Lord]. Papal bull. In: Weiland, L. Monumenta Germaniae Historica, Legum Sectio 4: Constitutiones et Acta Publica Imperatorum et Regum, Tomus I [Monuments of German History, Law Section 4: Constitutions and Public Acts of Emperors and Kings, Book I.]: Hannover, pp. 538-541. Impensis Bibliopolii Hahniani, Germany (1893)

Pope Paul VI: Lumen gentium [Light of nations]. Dogmatic Constitution of the Church. Acta Apostolicae Sedis 57, 5-71. Translation: Vatican website, Libreria Editrice Vaticana (1964)

Pope Paul VI: Ingravescentem aetatem [Increasing age]. Apostolic letter issued motu proprio. Acta Apostolicae Sedis 62, 810-813 (1970)

Pope Paul VI: Romano Pontifici Eligendo [Choosing the Roman Pontiff]. Apostolic constitution. Acta Apostolicae Sedis 67, 609-645 (1975)

Pope Pius X: Commissum nobis [Entrusted to us]. Apostolic constitution. In: Catholic Church., : Pii X Pontificis Maximi Acta, vol. III, pp. 289-292. Typographia Polyglotta Vaticana, Rome, Italy (1908) (1904a)

Pope Pius X: Vacante Sede Apostolica [Vacancy of the Apostolic See]. In: Catholic Church: Pii X Pontificis Maximi Acta, vol. III, pp. 239-288. Typographia Polyglotta Vaticana, Rome, Italy (1908) (1904b) 
Pope Pius XII: Vacantis apostolicae sedis [Of the vacancy of the Apostolic See]. Apostolic constitution. Acta Apostolicae Sedis 38, 65-99 (1945)

\section{Historical sources}

Adams, J.: Notes, by J.P. Adams, on Papal Elections and Conclaves from the 11th to the 21st Centuries. Personal website (2014)

Baumgartner, F.: Behind Locked Doors: A History of Papal Elections. Palgrave Macmillan, New York (2003)

Baumgartner, F.: Creating the rules of the modern papal election. Election Law J. 5, 57-73 (2006)

Duffy, E.: Saints and Sinners: A History of the Popes. Yale University Press, New Haven (1997)

Lonyay, K.: Rudolph, the Tragedy of the Mayerling. Charles Schribner's Sons, New York (1949)

Publisher's Note Springer Nature remains neutral with regard to jurisdictional claims in published maps and institutional affiliations. 